\title{
Food Technology and Preventive Medicine - Manufacture of Food for Special Regimes - Perspectives
}

\author{
Elevina Perez* \\ Institute of Food Science and Technology, Faculty of Sciences of the Central University of Venezuela
}

Received: March 06, 2014; Accepted: April 25, 2014; Published: April 28, 2014

*Corresponding author: Elevina Perez, Institute of Food Science and Technology, Faculty of Sciences of the Central, University of Venezuela, Tel: +584143146694; E-mail: perezee@hotmail.com

\begin{abstract}
It is relevant encourage the importance of the interrelation among the science and technology of food, nutrition and preventive medicine in the information for consumers, and in the development of products for special diets. Indeed, these concepts have been established from the age-old basis that are practiced, even today, with Chinese medicine, and is refreshed recently with the uses of the terms: food for special diet or functional foods. A high quality diet including functional food or functional ingredients, accompanied by physical activity and a non-smoking policy, is one of the most promising factors in primary and secondary prevention of NonCommunicable Diseases. Moreover, if the develop of products for special diets is encouraged, and practiced, it shall diminishing diseases and save hospital cost to the government.
\end{abstract}

Keywords: Food science and technology; Preventive medicine; Healthy foods; Special diets

\section{Food science and preventive medicine}

Since ancient times it has established the role of diet in the prevention of disease, Hippocrates (Greece, ca. 460 b.C. - 380 b.C), considered the father of modern medicine taught a scientific manner, many diseases and their treatment after detailed observation, postulating one of his important aphorisms: "Let your food be your medicine, and let your medicine be your food". At this time already Hippocrates was driving the idea of preventive medicine. He had conceived schemes by observation on environmental causes of the diseases, emphasizing not only in the diet, but on the generally the patient's life and how it should affect their health and convalescence [1].

The traditional Chinese medicine preventive basis, medical system with over 3000 years old [2,3] the aphorisms of the Hippocratic writing, and the philosophical principles "La vie est une fonction chimique" advanced by Lavoisier in the 18th Century (Antoine-Laurent Lavoisier, 1743-1794)[4]that establish the chemical basis of nutrition, converge in of four of the key nutrition concepts [5].

1. Foods provide energy (calories), nutrients, and other substances needed for growth and health. The most compelling reason for to eat is the need of calories, nutrients, and other substances supplied by foods;

2. Health problems related to nutrition originate within the cell. Cells are the main employer of the nutrients. All body process required for grown and health, take place within cells and the fluid that surrounds them. Functions of each cell are maintained by the nutrients it receives. Problems arise when a cells need for nutrients, differs from the available supply;

3. Poor nutrition can result from inadequate or excessive level of nutrient intake. For each nutrient, every individual has a range of optimal intake that produces the best level for cell and body function. On either side of the optimal range are levels of intake associated with impaired body function;

4. Humans have adaptive mechanisms for managing fluctuations in nutrient intake. Healthy humans are equipped with a number of adaptive mechanisms that partially protect the body from poor health due to fluctuation in dietary intake. In the context of nutrition, adaptive mechanism act to conserve nutrients when dietary supply is low and to eliminate them when they are present in excessively high amount.

It means that managing adequately the dietary regime of those individual from the earliest years of growing could prevent impaired body function and provide them a body healthy. However different situations on individual life could prevent that this panacea could be real. People have to be aware the food they are consuming and the balance to reach a healthy body, but that is not the real situation. According to [6] there are diverse factors that affect food choices by consumers: Individual physiological changes, psychological, cultural and cognitive factors, psychomotor ability, resources available, health and disease, convenience, drug-nutrient interactions. Consumers have limitations that must be overcome; even the health professionals have shown incongruence in its consumer habits. It was detected from a data analysis of survey health professionals of two distant regions [7] that the impact of the diet is a medium risk to the health of these individuals, because the predominant 
food of their diets, were the saturated fat and sodium, in addition to a low consumption of antioxidants, fiber and calcium. During academic training, the health professionals must receive basic knowledge about a healthy diet. It is assumed, that they should be privileged people with ideological and practical resources, to avoid habits eating, that affecting their own health.

A high quality diet including functional food or functional ingredients, accompanied by physical activity and a non-smoking policy, is one of the most promising factors in primary and secondary prevention of Non-communicable diseases (NCDs) [8). NCDs are widely associated to dietary habits; millions of deaths worldwide were due to NCDs, including cardiovascular diseases (coronary heart diseases, cerebrovascular diseases such as strokes, and peripheral vascular diseases), obesity, diabetes, cancers, etc. Most of these deaths were in low- and middle-income countries [8-23]. Providentially, NCDs could be prevented and controlled by an adequate managing the dietary regime of the individual.

Despite the consensus that several conditions in the lives of conventional consumers, or consumers with physiological or metabolic disorders could be prevented, and/or controlled with special dietary regimes, still there are not a very specific sector from industry and government, which engaged its production, research and policy to fill the deficient space of food for special regimes. Then, plus food production, targeting consumers with conventional diets, it also should be produced food for consumers with non-communicable diseases controlled with special diets regimes. It means that have to be produced foods with manufacture and sensorial quality using same procedures to obtain food similar to those produced either to conventional consumers or typical food in regions where the consumers live $[24,25]$. An example could be those microwavable dishes, but for diabetic or hypertension consumers, or pizzas for celiac, "catalinas" for diabetic. "Catalina is a kind of brown sugared regional bread consumed by Venezuelan people.

Before to setting out solutions, it is imperative to classify the consumers in the same order that have to be manufactured the foods. Thus consumer can be classified such as:

1. Conventional consumers;

2. Conventional consumers with special dietary regime: Infants, vegetarians, athletes, seniors are included in this line;

3. Consumers with physiological metabolic disorders advised or controlled with dietary food related to chronic non-communicable diseases (NCDs)

- Conventional consumers could be defined as those consumers that physiological are healthy, and another group that are conscious of the existent relationship between nutrition and health. This last group of consumer is reading literature in regards nutrition, food composition, diseases and its causes, etc. They are aware on the food composition, reading the food label and balancing of its consumptions. Today many young adults in Generation X engage in a variety of activities to learn more about food [26]. Adolescents also have conscience which harmfully could be the excessive consumption of some food ingredients. The majority of this consumers combine its elected food intake with a life style where include activities; such as sports, non-tabaquism, low liquor drinking, etc.

- Conventional consumers with special dietary regimes; such as infants, vegetarians, athletes, seniors among other, are those individual that despite not having a disease are needing a special dietary regimes due their status of live. Some on them such as the senior consumers, if not attended, they could pass to the status of the NCDs

- Controlled with dietary food because are suffering of a Chronic Non-Communicable diseases (NCDs). The World Health Organization [21], considered Non-Communicable Diseases as the leading cause of death and disability worldwide. Worldwide has rapidly increased the burden of NCDs, representing the largest health burden in developed countries, and a rapidly growing problem in developing countries. In most of the developed world, three out of four deaths are due to cardiovascular disease, cancer, accidents and other illnesses such as diabetes, hypertension, chronic respiratory disease, osteoporosis and some musculoskeletal disorders, such as major problems. Chronic diseases are increasing worldwide, regardless of region or social class. One of the induced disorders by ingestion of psychotropic for medication, or addiction need to be also referred. A major concern about the increase of metabolic disorders rates associated with medication use to treat severe mental illnesses (SMI) exist. Psychotropic medications have come to play an increasingly central role in the treatment of psychiatric disorders and many patients consuming psychotropic drugs as medication tend to become obese and they are sensitive to the diseases mentioned above $[27,28]$.

It is of imperative reflection, that despite the topic is quite discussed at the literature, and by consensus, the consequences of these diseases can be reversible or irreversible unchangeable controllable, there exist not many practical disposition from those taking decisions.

In this context the role of nutrition, education and its links to food science and technology is to induce consumers to improve their diet and produce food in order to provide resources available and convenience to the consumers.

This simple goal is not an easy task. Individuals should receive information, develop skills to integrate and apply information and be encouraged to apply for it. That is, in nutrition education, there must be a multidisciplinary interplay, which shall include food science, nutrition and preventive medicine. Likewise, nutrition should not be considered as an isolated factor, but as a component of a lifestyle. It means that improving our diet in conjunction with other positive behavioral changes, such as, 
health and physical activity, can have a better impact than just improving nutrition. Moreover, food processors have to be encouraged by government policy in order to produce foods for special regimes, and completely fill the empty that today exist for these consumers.

As was discussed before, the close relationship between health and food is recognized, reason why, from a time ago, it has been developing products and foods modified in composition by reduction, elimination or addition of nutrients in order to help prevent deficiencies and prevent excesses harmful health. However the efforts are no important and must be deepened by research entities, government and industries.It has even been defined a term: "Foods for Special Dietary Uses". They are those foods which are specially processed or formulated to satisfy particular dietary requirements which exist because of a particular physical or physiological condition and/or specific diseases and disorders and which are presented as such. The composition of these foodstuffs must differ significantly from the composition of ordinary foods of comparable nature, if such ordinary foods exist. [29].

The Food and Drug Administration U.S. and in the Code of Federal Regulations, 2 define the use of special dietary foods (Committee on Nutrition of the American Academy of Pediatrics) [30] such as:

a) Uses for supplying particular dietary needs which exist because of a physical, physiological, pathological, or other condition, including but not limited to the conditions of diseases, convalescence, pregnancy, lactation, allergic hypersensitivity to food, [ and be ] underweight and overweight ;

b) Uses for supplying particular dietary needs which exist by reason of age, including but not limited to the ages of infancy and childhood;

c) Uses to complement or strengthen the usual or ordinary diet with any vitamin, mineral, or other dietary property. Any particular use of a food is special, regardless of whether such food also purports to be or is represented for general dietary use.

Ministry of Health, Labour and Welfare (MHLW) [31] have defined the Food for Specified Health Uses (FOSHU); as foods containing ingredient with functions for health and officially approved to claim its physiological effects on the human body. FOSHU is intended to be consumed for the maintenance/ promotion of health or special health uses by people who wish to control health conditions, including blood pressure or blood cholesterol. In order to sell a food as FOSHU, the assessment for the safety of the food and effectiveness of the functions for health is required, and the claim must be approved by the MHLW.

Science and food technology is a multidisciplinary field that has an extensive field or range, extending from the study of food selection, manufacturing, and reaching the effects of a specific component of health or functional ingredient. Education, industry, and consumers play together a role in nutrition policy.
The food industry and food research, have a social responsibility to implement and disseminate education in the community. His responsibilities include initiatives, funds, and disseminate research based on scientific knowledge toward the professionals, and consumers. Industry must to develop healthy products that include in their composition, the nutrition label and the ingredient list. Another responsibility of the industry, shall define as the consumer will develop the skills to use the information being supplied and motivate them to use it, adapting this information to each specific group. For this purpose you must use a lot of imagination and creativity, in fact the food industry has the highest chance, than any other sector to inform effective messages through advertisements. Moreover, the academy must promote and conduct research related to cases of health and nutrition, study the market, and consumers with their needs and realities, share and interrelate information obtained in order to have a close connection problems related to industry and society. There exist a large consumer demand and a vast scientific knowledge of the food constituents, which can prevent disease. Since ancient times, man dreams of defeating disease and thus prolongs its life. It is a currently consensus related to disease prevention, anti -aging, energy, and immunity, that it has the full attention of the consumers.

The marketing of food products for disease prevention and treatment is common place. It is for this reason that the concepts of diet and special dietary functional foods arise. The tender must be developed for a consumer with problems of cardiovascular disease, hyperlipidaemia, diabetes, obesity, stress, heart disease, osteoporosis, high cholesterol, cancer. The vision of food as preventive medicine continues to grow. The presence of phyto chemicals and nutrients in vegetables and grains inducing consumer products will continue to move closer to healthy states through food. At the same time, the market for "nutraceuticals" or functional and mature special schemes offering food and beverages, not only to improve the lifestyle and sports, but for those consumers with risk factors and chronic conditions major diseases [32-35].

\section{Conclusion}

There exist a narrow relationship among the science and technology of food, nutrition and preventive medicine. It is by consensus that if it is adequately managed to the dietary regime of those individuals, from the earliest years of growing could prevent impaired body function and provide them a body healthy. Food processors have to be encouraged by government policy in order to produce foods for special regimes, and completely fill the empty that today exist for these consumers. It has also to be addressed to develop of the food for special regimes using the local raw material and elaborating folkloric food. Although this concept has been handled long time ago, their understanding has been slow, and in the last decades that it has been giving importance with the definition of functional foods. Encouraging develop of products for special diets, will diminish diseases, and for hence will save hospital cost to the government. 


\section{References}

1. Grammaticos PC, Diamantis A (2008) Useful known and unknown views of the father of modern medicine, Hippocrates and his teacher Democritus. Hell J Nucl Med 11(1): 2-4.

2. Lu A, Jiang M, Zhang C, Chan K (2012) An integrative approach of linking traditional Chinese medicine pattern classification and biomedicine diagnosis. J Ethnopharmacol 141(2): 549-556.

3. Zhang C, Jiang M, Guo H, Zheng G, Yang J, et al. (2012) Chinese Herbal Medicines for Rheumatoid Arthritis. Advances in Botanical Research 62: 273-313.

4. Hartmann PE, Jillian L, Sherriff JL, Mitoulas LR ( 1998) Homeostatic Mechanisms that Regulate Lactation during Energetic Stress. J Nutr128(2): 394S-399S.

5. Brown JE (2010) Nutrition Now. Wadsworth Cengagae Learning, USA pp 1-6.

6. Jackson P (2009) Chapter 10 Nutritional assessment and needs Foundation Studies for Caring and Foundation Skills for Caring. In:Alan Glasper, Gill McEwing (eds) \& Jim Macmillan Houndmills, Basingstoke, Hampshire, RG21 6XS England Richardson.

7. Lares M, Pérez E, Schroeder M, Brito S, Hernandez P, et al. (2011) Evaluation and Comparison of feeding behavior of health professionals in two hospital centers. Venezuelan Archives of Pharmacology and Therapeutics 30 (4): 67-71.

8. Wagner KH, Brath $\mathrm{H}$ (2012) A global view on the development of noncommunicable diseases. Prev Med 54(1): S38-S41.

9. Seclén S, Leey J, Villena A, Herrera B, Menacho J, et al. (1999) Prevalencia de obesidad, Diabetes Mellitus, hipertensión arterial e hipercolesterolemia como factores de riesgo coronario y cerebrovascular en población adulta de la costa, sierra y selva del Perú. Acta Médica Peruana 17(1): 8-12.

10. Puska P (2002) Nutrition and global prevention on non-communicable diseases. Asia Pac J Clin Nutr 11(9): S755-S758.

11. WHO (2003) Diet, Nutrition and Prevention of Chronic Diseases WHO Technical Report Series 916. Technical Report of a Joint WHO / FAO Expert.

12. Kelishadi R, Alikhani S, Delavari A, Alaedini F, Safaie A, et al. (2007) Obesity and associated lifestyle behaviours in Iran: findings from the First National Non-communicable Disease Risk Factor Surveillance Survey. Public Health Nutr 11(3): 246-251.

13. Palomo GI, Icaza NG, Mujica EV, Nunez FL, Leiva ME (2007) Prevalence of cardiovascular factors Riesgo classic adult population of Talca, Chile, 2005. Chile Medical Journal 135 (7): 904-912.

14. Velazquez Monroy O, Barinagarrementería Aldatz FS, Rubio Guerra AF, Verdejo J, Méndez Bello MA, et al. (2007) Morbidity and mortality by ischemic heart disease and stroke in Mexico. 2005. Arch Cardiol Mex 77(1): 31-39.

15. Laurentin A, Schnell M, Tovar J, Domínguez Z, Pérez BM, et al. (2007) Nutrition transition: between malnutrition and obesity. Anales Venezolanos de Nutrición 20 (1): 47-52.

16. WHO (2010) Report on the global status of non communicable diseases transmisibles.

17. Schmidt MI, Duncan BB, Azevedo e Silva G, Menezes AM, Monteiro CA, et al. (2011) Chronic non-communicable diseases in Brazil: burden and current challenges. Lancet 377 (9781): 1949-1961.
18. Jova Morel R, Rodríguez Salva, A, Díaz Piñera A, Balcindes Acosta S, Sosa Lorenzo, et al. (2011) Models of care for patients with chronic non-communicable diseases in Cuba and the world. EDISAN 15 (11): 1609-1620.

19. WHO (2011) Global status report on non communicable diseases 2010. Geneva.

20. Mohan V, Sandeep S, Deepa R, Shah B, Varghese C (2012) Epidemiology of type 2 diabetes: Indian scenario. Indian J Med Res 136 (4): 217-230.

21. WHO (2012) WHO = World Health Organization. World Health Statistics 2012 .

22. Reche L (2013) Manual Primary Care Management Pathologies Ministry of Health of the Province of Buenos Aires. Ministry of Health of Argentina. Introduction Epidemiology of Noncommunicable Diseases.

23. OPS-OMS (2013) Pan American Health Organization and World Health Organization WHO. Cancer in the Americas country profiles.

24. Pérez E (2010) Food Technology in Medicine? Perspectives in Venezuela in the manufacture of special systems. 11(1-2): 6-10.

25. Pérez EE, Mahfoud A, Domínguez CL, Guzman R (2013) Roots, Tubers, Grains and Bananas; Flours and Starches. Utilization in the Development of Foods for Conventional, Celiac and Phenylketonuric Consumers. J Food Process Technol 4 (3): 1-6.

26. Miller JD (2012) Food Shared, Prepared, Organic, and Genetically Modified. GenerationX Report. A quarterly Research report from the longitudinal study of American youth.

27. Schroeder M, Pérez E, Lares M, Guzman P, Brito S (2012) Integrated health care, use of psychotropic medications and soy products as alternative in patients who suffer from schizophrenia and metabolic syndrome. Sindrome Cardiormetabólico 2(2): 41-47.

28. Schroeder M, Pérez E, Lares M, Brito S, Cira L (2010) A review: Association of Preventable Medical Conditions, Healthy Nutrition, the Ingestion of Psychotropic Medication and People who suffer from Severe Mental Illnesses. Revista Archivos Venezolanos de Farmacología y Terapéutica 29(2): 20-25.

29. CODEX Alimentarius (1985) Commission Food and Agriculture Organization of the United Nations World Health Organization 1985. General standard for the labeling of and claims for prepackaged foods for special dietary uses. CODEX STAN 146.

30. Committee on Nutrition American Academy of Pediatrics (2003) Reimbursement for Foods for Special Dietary Use. Pediatrics Official Journal of the American Academy of Pediatrics 5(1): 1117-1118.

31. Japon (2010) Ministry of Health, Labour and Welfare.

32. Hilliam M (1996) Functional foods: the Western consumer viewpoint. Nutr Rev 54(11): S189-S194.

33. Hilliam M (1998) The market for functional foods. International Dairy J 8(5): 349-353.

34. Hilliam M (2000) Functional food: how big is the market? World of Food Ingredients 12: 50-53.

35.Verbeke W (2005) Consumer acceptance of functional foods: sociodemographic, cognitive and attitudinal determinants. Food Quality and Preference 16: 45-57. 